\title{
A study on the effect of salinity stress on the chlorophyll content of certain rice cultivars of Kerala state of India
}

\author{
K. T. Chandramohanan, V. V. Radhakrishnan, E. Abhilash Joseph, K. V. Mohanan \\ Department of Botany, University of Calicut, Kerala, India
}

\section{Email address:}

chandrubrennen@gmail.com (K. T. Chandramohanan),rkvadakkan@gmail.com (V. V. Radhakrishnan), abhilashjosephe@gmail.com (E. A. Joseph),drkvmohanan@rediffmail.com (K. V. Mohanan)

\section{To site this article:}

K.T. Chandramohanan, V.V. Radhakrishnan, E. Abhilash Joseph, K.V. Mohanan. A Study on the Effect of Salinity Stress on the Chlorophyll Content of Certain Rice Cultivars of Kerala State of India. Agriculture, Forestry and Fisheries. Vzol. 3, No.2, 2014, pp. 67-70.doi: 10.11648/j.aff.20140302.13

\begin{abstract}
Photosynthetic efficiency of a crop species depends upon factors like leaf area, chlorophyll content, stomatal exposure, etc. The present study was an attempt to assess the impact of salt stress on the chlorophyll content of sevenpopular rice cultivars grown in one of the saline rice habitatsof Kerala state of India such as Kuthitru, Kuttusan, Orkazhama, Chovvarian, Orthadian, Ezhome-1 and Ezhome-2.The results showed general reduction in chlorophyll content in all the seven cultivars studied under salt stress. The cultivars Chovvarianand Orthadian exhibited comparatively lesser quantum of negative variation in chlorophyll content under salt stress indicating their potential to grow and perform moderately well even under higher levels of salinity.
\end{abstract}

Keywords: Rice, Salt Stress, Chlorophyll Content

\section{Introduction}

Rice is a salt sensitive crop species for which soil salinity is a major factor restricting yield throughout substantial areas of Africa and south and south-eastern Asia.Several physiological pathways like photosynthesis, respiration, nitrogen fixation and carbohydrate metabolism have been observed to be affected by high salinity.Salinity stress is a major constraint to cereal production worldwide. Rice is a salt sensitive crop, but it is the only cereal that has been recommended as a desalinization crop due to its ability to grow well under flooded conditions, and because the standing water in rice fields can help leach the salts from the topsoil to lower levels [1].For centuries, farmers have grown salt tolerant rice varieties in saline tracts in India, Burma, Thailand, Indonesia and the Philippines. But yields were only about 1 tha $^{-1}$. Recognition of the potential of saline lands for rice production has prompted an international effort to breed salt tolerant varieties with disease and insect resistance and high yield potential [2].

Earlier studies conducted under controlled conditions reported that salt injury in rice plant was caused by both osmotic imbalance and accumulation of chloride ions [3]. Other studies, however, indicated that injury was due to excessive Sodium uptake and chloride is tolerated over a wide range of concentrations [4]. The disruptive effect of $\mathrm{Na}$ and its interference with the role of cytoplasmic K preempted $\mathrm{Cl}$ toxicity. Moreover, Na-K imbalance adversely affected grain yield [5].

Salinity, a serious problem affecting one third of all the irrigated land in the world [6], impairs normal growth and limits the realization of yield potential of crop varieties.Rice is considered susceptible to salinity particularly during the early vegetative phase and later at the reproductive stage [6,7].Rice genotypes vary considerably in salinity tolerance and that is principally due to additive gene effects [8].As per the classification of crop tolerance to salinity, the rice crop is within the sensitive division from $0 \mathrm{dSm}^{-1}$ to $8 \mathrm{dSm}^{-1}\left(0-8 \mathrm{mmhocm}^{-1}\right)$ [9].There are two essential parameters sufficient for expressing salt tolerance. The first one is threshold meaning the maximum allowable salinity without yield reduction and the next is slope meaning the percent of yield reduction per unit increase in salinity beyond the threshold. The threshold and slope of rice (Oryza sativa) have been assessed as $3 \mathrm{dSm}^{-1}$ $\left(3 \mathrm{mmhocm}^{-1}\right)$ and $12 \%$ per $\mathrm{dSm}^{-1}$ of saturated soil extract $\left(\mathrm{EC}_{\mathrm{e}}\right)$, respectively [6].Relative salt tolerance of rice at $50 \%$ yield and at $50 \%$ emergence are $3.6 \mathrm{dSm}^{-1}$ and $18 \mathrm{dSm}^{-1}(18$ mmhocm $^{-1}$ ) of $\mathrm{EC}_{\mathrm{e}}$ respectively [10]. During the monsoon season when sufficient fresh water is available, the salts are 
dissolved and diluted in the surface soil layers and washed out from plants' shallow root zone [11]. Phenotypic resistance to salinity is expressed as the ability to survive and grow in a salinized medium. Selection of salt tolerant cultivars is one of the most effective methods to increase the productivity of saline soils. Generally, the trend and magnitude of adverse changes vary within species, varieties/genotypes according to the level of salinization.

Although yield is the result of interaction in the genetic makeup of genotypes, it has been suggested that by increasing photosynthetic efficiency, crop production could be increased [12].Photosynthetic efficiency depends upon factors like leaf area, chlorophyll content, stomatal exposure, etc.The present study was an attempt to assess the impact of salt stress on the chlorophyll content of seven popular rice cultivars grown in the saline habitat of Kerala state of India such as Kuthitru, Kuttusan, Orkazhama, Chovvarian,Orthadian, Ezhome-1 and Ezhome-2.

\section{Materials and Methods}

The experiment was carried out in the experimental rainout poly house of the Department of Botany of University of Calicut, Kerala, India located at $11^{0} 35^{\prime} \mathrm{N}$ latitude and $75^{\circ} 48^{\prime} \mathrm{E}$ longitudeduringthe first crop season of 2011-12.Sevensalinity tolerant rice cultivars namely Kuthitru, Kuttusan, Orkazhama, Chovvarian,Orthadian, Ezhome-1 and Ezhome-2were used for the study.They were screened under two salt concentrations, i.e., $3 \mathrm{dSm}^{-1}$ (3 mmhocm $\left.^{-1}\right)$ and $6 \mathrm{dSm}^{-1} \quad\left(6 \quad \mathrm{mmhocm}^{-1}\right)$ concentrations. Three plants each of the seven salinity tolerant rice varieties were grown in polythene covers lined with cotton cloth, placed in salt concentrations of $3 \mathrm{dSm}^{-1}$ $\left(3 \mathrm{mmhocm}^{-1}\right), 6 \mathrm{dSm}^{-1}\left(6 \mathrm{mmhocm}^{-1}\right)$ plus control.The experiment was designed as per the screening technique developed in IRRI [13].Three plants each of the seven rice cultivars were planted in polythene covers lined with cotton cloths, specially arranged for treatment with different salt concentrations of $3 \mathrm{dSm}^{-1}\left(3 \mathrm{mmhocm}^{-1}\right), 6 \mathrm{dSm}^{-1}(6$ mmhocm ${ }^{-1}$ )plus control (tap water).Holes of 3-4 mm diameter were made $2 \mathrm{~cm}$ apart on the polythene cover in concentric circles to allow entry of salinized water so as to soak the soil.The bags were filled with paddy soil + river sand + enriched compost in 4:1:1 proportion. Initially, the soil level was about $1 \mathrm{~cm}$ above the topmost circle of holes. With levelled soil, polythene bags were placed in large trays made using tarpaulin sheets, filled with tap water.This served as water bath.Separate water baths were maintained for the different salt concentrations and control. The water level was maintained the same as the soil level.The soil then began to settle as it absorbed water and extra soil was added to maintain the correct soil level.Seven day old seedlings were planted on soil surface of each pot.The water level was raised to about $1 \mathrm{~cm}$ above soil and maintained continuously and the plants were protected from pests and diseases. When the seedlings were 21 days old, water in the water baths was completely siphoned out in the case of the treatments.After a 12 hour break the soil became completely dry. Salinized water solutions made up to the desired EC levels of 3 and $6 \mathrm{dSm}^{-1}$ were prepared by stirring and dissolving table salt $(\mathrm{NaCI})$ in water.The trays were filled with salinized water solutions of the required concentrations until the soil in the experimental bags got completely soaked with saline water and the water level raised to $1 \mathrm{~cm}$ in the bags. The water level in the polythene bags was maintained $1 \mathrm{~cm}$ above soil level by adding sufficient quantity of tap water as and when required. Fertilizer top dressing was carried out by applying $1 \mathrm{~g} \mathrm{NPK}$ (18:18:18) per plant at 15 days' intervals starting from the $30^{\text {th }}$ day till flowering.

Leaves previous to flag leaves of the mother tiller of each plant were collected just before panicle emergence.Freshly cut pieces of control as well as treated plant leaves were washed with water and blotted between sheets of filter paper.To estimate chlorophyll, $80 \%$ acetone was used as the extracting medium.Enough precautions were taken to avoid any exposure of the extract to light.A quantity of $0.05 \mathrm{~g}$ of fresh leaf sample was weighed in an electronic balance and crushed using mortar and pestle in 3 $\mathrm{ml}$ of $80 \%$ acetone $(\mathrm{w} / \mathrm{v})$. Then the homogenate was centrifuged at $5000 \mathrm{rpm}$ for 10 minutes and the supernatant was collected.The residue was again washed with $80 \%$ acetone and centrifuged.The process wasrepeated till the pellet became colourless. The final volume of the pooled supernatant was noted.The absorbance was read at $663 \mathrm{~nm}$, $646 \mathrm{~nm}$ and $750 \mathrm{~nm}$ against the solvent blank $(80 \%$ acetone).Then the amount of chlorophyll present in the extract was calculated in $\mu \mathrm{g}$ chlorophyll per gram fresh weight [14] using the following formula:

$$
\begin{aligned}
& \text { Chlorophyll a } \mu \mathrm{g} / \mathrm{g} \text { fresh weight } \\
& =\frac{12.69\left(A_{663}-A_{750}\right)-2.69\left(A_{646}-A_{750}\right) \times \text { Volume }}{\text { Fresh weight of the sample }} \\
& \text { Chlorophyll b } \mu \mathrm{g} / \mathrm{g} \text { fresh weight } \\
& =\frac{22.9\left(A_{646}-A_{750}\right)-4.68\left(A_{663}-A_{750}\right) \times \text { Volume }}{\text { Fresh weight of the sample }} \\
& \text { Total Chlorophyll } \mu \mathrm{g} / \mathrm{g} \text { fresh weight } \\
& =\frac{20.12\left(A_{646}-A_{750}\right)+8.02\left(A_{663}-A_{750}\right) \times \text { Volume }}{\text { Fresh weight of the sample }}
\end{aligned}
$$

The data obtained were statistically analyzed for comparison. Analysis of variance was carried out for the purpose as suggested by Singh and Choudhary (1985) [15].

\section{Results and Discussion}

All the seven cultivars under study namely Kuthitru, Kuttusan, Orkazhama, Chovvarian,Orthadian, Ezhome-1 and Ezhome-2 were screened under two salt concentrations, i.e., $\quad 3 \mathrm{dSm}^{-1}\left(3 \mathrm{mmhocm}^{-1}\right)$ and $6 \mathrm{dSm}^{-1}\left(6 \mathrm{mmhocm}^{-}\right.$ 
$\left.{ }^{1}\right)$ concentrations and the results are presented (Table 1) and discussed below.

In Kuthiru, chlorophyll a, chlorophyll b and total chlorophyll content showed highly significant reduction over the control under salt stress both at $3 \mathrm{dSm}^{-1}$ (3 $\left.\mathrm{mmhocm}^{-1}\right)$ and $\quad 6 \quad \mathrm{dSm}^{-1} \quad\left(6 \quad \mathrm{mmhocm}^{-1}\right)$.However, Chlorophyll $\mathrm{b}$ showed a higher percentage of reduction when compared to chlorophyll a. Percentage of reduction increased proportionate to increase in salt concentration.In Kuttusan also, chlorophyll a, chlorophyll b and total chlorophyll content showed highly significant reduction over the control under salt stress both at $3 \mathrm{dSm}^{-1}$ (3 mmhocm $\left.{ }^{-1}\right)$ and $6 \mathrm{dSm}^{-1}\left(6 \mathrm{mmhocm}^{-1}\right)$. However, at $3 \mathrm{dSm}^{-}$ ${ }^{1}$, the percentage of reduction was almost same in the case of chlorophyll a, chlorophyll b and total chlorophyll content. Reduction of chlorophyll a and total chlorophyll content was relatively high at $6 \mathrm{dSm}^{-1}$.In Orkazhama, chlorophyll a, chlorophyll $\mathrm{b}$ and total chlorophyll content showed highly significant reduction over the control under salt stress both at $3 \mathrm{dSm}^{-1}\left(3 \mathrm{mmhocm}^{-1}\right)$ and $6 \mathrm{dSm}^{-1}(6$ mmhocm $\left.{ }^{-1}\right)$. Percentage of reduction was comparatively low when compared to the native cultivars Kuthiru,
Kuttusan and Orthadian.Higher salt concentration caused proportionate reduction in chlorophyll content.In the case of Chovvarian,chlorophyll a, chlorophyll b, and total chlorophyll content showed significant reduction over the control under both the salt concentrations studied.The percentage of reduction increased proportionately in relation to increase in salt concentration.In Orthadian also, chlorophyll a, chlorophyll $\mathrm{b}$ and total chlorophyll content showed significant reduction over the control under salt stress both at $3 \mathrm{dSm}^{-1}\left(3 \mathrm{mmhocm}^{-1}\right)$ and $6 \mathrm{dSm}^{-1}$ (6 mmhocm ${ }^{-1}$ ). However, it was observed that this variety showed the minimum reduction in chlorophyll content under salt stress.The negative variation in chlorophyll content in the case of $3 \mathrm{dSm}^{-1}$ was not statistically significant. In Ezhome-1 and Ezhome-2 also, chlorophyll a content,chlorophyll $\mathrm{b}$ content and total chlorophyll content exhibited significant variation. In Ezhome-1 the percentage of reduction in chlorophyll $b$ content was lower than the percentage of reduction in the other types of chlorophyll.In Ezhome-2 the pattern of reduction in the case of different types of chlorophyll was more uniform. At $6 \mathrm{dSm}^{-1}$ (6 $\mathrm{mmhocm}^{-1}$ ), the reductionwas proportionatelyhigher.

Table 1. Chlorophyll $a, b$ and total chlorophyll content $\left(\mu \mathrm{g} \mathrm{g}^{-1}\right)$ of the leaves in the case of the different rice cultivars studied as affected by different salt concentrations.

\begin{tabular}{|c|c|c|c|c|c|c|c|}
\hline \multirow{2}{*}{ Pigment } & \multicolumn{3}{|c|}{ Treatments } & \multirow{2}{*}{$\mathrm{CD} @ 5 \%$} & \multirow{2}{*}{ CD@1\% } & \multirow{2}{*}{$\begin{array}{l}\% \text { of negative variation } \\
\text { over control at } 3 \mathrm{dSm}^{-1}\end{array}$} & \multirow{2}{*}{$\begin{array}{l}\% \text { of negative variation } \\
\text { over control at } 6 \mathrm{dSm}^{-1}\end{array}$} \\
\hline & Control & $3 \mathrm{dSm}^{-1}$ & $6 \mathrm{dSm}^{-1}$ & & & & \\
\hline \multicolumn{8}{|c|}{ 1. Kuthiru } \\
\hline Chlorophyll a & 636.59 & 540.39 & 394.66 & 100.34 & 152.00 & 15.11 & 38.00 \\
\hline Chlorophyll b & 563.63 & 345.34 & 329.85 & 167.78 & 254.17 & 38.73 & 41.48 \\
\hline Total chlorophyll & 1197.52 & 883.97 & 722.92 & 163.00 & 246.92 & 26.18 & 39.63 \\
\hline \multicolumn{8}{|c|}{ 2. Kuttusan } \\
\hline Chlorophyll a & 649.37 & 481.27 & 304.09 & 54.55 & 82.63 & 25.89 & 53.17 \\
\hline Chlorophyll b & 571.25 & 423.44 & 413.57 & 80.69 & 122.23 & 25.87 & 27.60 \\
\hline Total chlorophyll & 1217.89 & 902.69 & 718.51 & 81.38 & 123.29 & 25.88 & 41.00 \\
\hline \multicolumn{8}{|c|}{ 3. Orkazhama } \\
\hline Chlorophyll a & 550.34 & 475.86 & 337.01 & 47.17 & 71.46 & 13.53 & 38.76 \\
\hline Chlorophyll b & 498.97 & 446.47 & 190.90 & 48.96 & 74.17 & 10.52 & 61.74 \\
\hline Total chlorophyll & 1046.93 & 920.21 & 526.91 & 87.42 & 132.43 & 12.10 & 49.67 \\
\hline \multicolumn{8}{|c|}{ 4. Chovvarian } \\
\hline Chlorophyll a & 531.75 & 405.15 & 271.40 & 52.18 & 79.04 & 23.81 & 48.96 \\
\hline Chlorophyll b & 446.75 & 317.73 & 258.18 & 62.71 & 95.00 & 28.88 & 42.21 \\
\hline Total chlorophyll & 976.34 & 721.33 & 528.35 & 74.71 & 113.19 & 26.12 & 45.88 \\
\hline \multicolumn{8}{|c|}{ 5. Orthadiyan } \\
\hline Chlorophyll a & 541.39 & 517.17 & 451.62 & 39.94 & 60.50 & 4.47 & 16.58 \\
\hline Chlorophyll b & 441.51 & 420.36 & 365.81 & 66.47 & 100.70 & 4.79 & 17.15 \\
\hline Total chlorophyll & 980.76 & 935.48 & 815.65 & 87.84 & 133.07 & 4.62 & 16.83 \\
\hline \multicolumn{8}{|c|}{ 6. Ezhome 1} \\
\hline Chlorophyll a & 713.67 & 611.24 & 543.93 & 83.31 & 126.21 & 14.35 & 23.78 \\
\hline Chlorophyll b & 555.43 & 444.60 & 347.54 & 72.83 & 110.34 & 19.95 & 37.43 \\
\hline Total chlorophyll & 1266.38 & 1053.63 & 889.70 & 48.76 & 73.87 & 16.80 & 29.74 \\
\hline \multicolumn{8}{|c|}{ 7. Ezhome 2} \\
\hline Chlorophyll a & 668.66 & 521.11 & 456.96 & 52.60 & 79.69 & 22.07 & 31.66 \\
\hline Chlorophyll b & 494.91 & 463.59 & 413.71 & 78.01 & 118.18 & 6.33 & 16.41 \\
\hline Total chlorophyll & 1161.13 & 982.49 & 868.70 & 104.87 & 158.86 & 15.38 & 25.18 \\
\hline
\end{tabular}


The above study has revealed that salt stress resulted in a general decline in chlorophyll content in all the cultivars of rice studied.Djanaguiraman and Ramadass[16]have reported that Chlorophyll $b$ showed higher level of reduction in comparison to chlorophyll a. Similar studies were also carried out by Ashraf and Yousafali [17] and Ali et al.[18] and showed that the chlorophyll content (chlorophyll a, b and total) of rice leaves was generally reduced under high salinity. However, the present study showed that the reduction in chlorophyll content was variety specific and some cultivars like Chovvarian and Orthadian showed comparatively lesser quantum of negative variation in chlorophyll content thus indicating their potential to grow and perform moderately well even under higher levels of salt stress.

\section{References}

[1] Lafitte H.R., Ismail J. and Bennett A., 2004. Abiotic stress tolerance in rice for Asia: progress and the future. In:'New Directions for a Diverse Planet', Proc. 4th International Crop Science Congress. pp. 1-17.

[2] Ikehashi H. and Ponnamperuma F.N., 1978. Varietal tolerance of rice for adverse soils. In: 'Soils and Rice'. IRRI, Manila, Philippines. pp. 801-825.

[3] Shimose N., 1963. Physiology of salt injury in crops. I: Effect of iso-osmotic pressure due to Sodium chloride and Sodium sulfate on the growth and absorption of minimal elements by rice plants.J.Sci. Soil Tokyo 34: 107-111.

[4] Clarkson D.T. and Hanson J.B., 1980. The material nutrition of higher plants. Annual Rev. Plant Physiol. 31: 239.

[5] Devitt D., Jarreli W.M. and Stevens K.L., 1981. SodiumPotassium ratios in soil solution and plant response under saline conditions. Soil Sci. Soc. Am. J. 45: 80-86.

[6] Maas E.V. and Hoffman G.J., 1977. Crop salt tolerance: Current assessment. ASCEJ Irrig. Drain Div. 103:115-134.

[7] Shannon M.C., Rhoades J.D., Draper J.H., Scardaci S.C. and Spyres M.D., 1998. Assessment of salt tolerance in rice cultivars in response to salinity problems in California. Crop Science 38(2): 394-398.

[8] Sahi C., Singh A., Kumar K., Blumwald E. and Grover A., 2006. Salt stress response in rice: Genetics, molecular biology and comparative genomics. Functional and Integrative Genomics 6(4): 263-284.

[9] [Maas E.V., 1986. Salt tolerance of plants. Applied Agric. Res. 1: 12-26.

[10] Wahhab A., 1961. Salt tolerance of various varieties of agricultural crops at the germination stage. In: 'Salinity Problems in the Arid Zone. (Proc. Teheran Symposium on Arid Zone Research, 14'. UNESCO. pp. 185-192.

[11] Pearson G.A. and Ayres S.D., 1960. Rice as a crop for salt affected soils in process of reclamation. USDA Prod. Res. Rep. 43. p.13.

[12] Ashraf M.Y., Khan A.H. and Naqvi S.S.M., 1995. Relationships of chlorophyll content and leaf area with grain yield in wheat genotypes. Indian J. Plant Physiol. 38(2):162-163.

[13] Gregorio G.B., Senadhira D. and Mendoza R.D., 1997.Screening rice for salinity tolerance. IRRI Discussion Paper Series No. 22.IRRI, Manila, Philippines. p.30.

[14] Arnon D., 1949. Copper enzymes in isolated chloroplastsPolyphenoloxidase in Beta vulgaris.Plant Physiol. 24(1): 115.

[15] Singh R.K. and Choudhary B.D., 1985. Biometrical Methods in Quantitative Genetic analysis. Kalyani Publishers, New Delhi, India. p. 318.

[16] Djanaguiraman M. and Ramadass R., 2004. Effect of salinity on chlorophyll content of rice genotypes.Agric. Sci. Digest. 24(3): 178-181.

[17] Ashraf Y.A. and Yousafali, 1998. Effect of salinity on growth, chlorophyll content and flag leaf area of rice (Oryza sativa L.) genotypes. IRRN. 23(2): 33-35.

[18] Ali Y., Aslam Z., Ashraf M.Y. and Tahir G.R., 2004. Effect of salinity on chlorophyll concentration, leaf area, yield and yield components of rice genotypes grown under saline environment. Int. J. Envnmntl. Sci. and Tech. 1(3): 221-225. 